Brazilian Journal

of Chemical

ISSN 0104-6632

Engineering

Printed in Brazil

www.scielo.br/bjce

Vol. 34, No. 03, pp. 747 - 758, July - September, 2017

$($ (c) $)$ EY

dx.doi.org/10.1590/0104-6632.20170343s20150700

\title{
HETEROGENEOUS PHOTO-FENTON AND PHOTOCATALYTIC DEGRADATION STUDIES OF 2-CHLORO-4-NITROPHENOL (2CL4NP) USING FOUNDRY SAND AND $\mathrm{TIO}_{2} \mathrm{COATED} \mathrm{CEMENT/}$ CLAY BEADS
}

\author{
Kashish Aggarwal $^{1}$, Anoop Verma ${ }^{1 *}$, Palak Bansal ${ }^{1}$ and Amanjit Singh ${ }^{1}$ \\ ${ }^{1}$ School of Energy and Environment, Thapar University, Patiala, Punjab, India \\ E-mail: anoop.kumar@thapar.edu; Phone: +91 175 2393045; Fax: +91 1752393738
}

(Submitted: November 2, 2015; Revised: April 12, 2016; Accepted: April 18, 2016)

\begin{abstract}
Cement and clay beads coated with $\mathrm{TiO}_{2}$ were used for the photo-degradation and mineralization of 2-chloro-4-nitrophenol (2Cl4NP) along with a heterogeneous solar photo-Fenton process using foundry sand (FS) as the iron source. The degradation process was optimized using slurry photocatalysis where $96 \%$ degradation of $2 \mathrm{Cl} 14 \mathrm{NP}$ was achieved in $120 \mathrm{~min}$ at optimized conditions of $\mathrm{C} 0=50 \mathrm{mgL}^{-1}, \mathrm{pH}=4,0.75 \mathrm{gL}^{-1} \mathrm{TiO}_{2}$ and $\mathrm{H}_{2} \mathrm{O}_{2}=0.1$ $\mathrm{mL} / 200 \mathrm{~mL}$. Degradation of 2Cl4NP was analyzed through HPLC along with UV-Visible spectrophotometer at 266 $\mathrm{nm}$. The degradation of $68 \%$ and $52 \%$ of $2 \mathrm{Cl} 4 \mathrm{NP}$ was attained in fixed-bed photocatalysis using cement and clay beads, respectively. The durability studies of cement and clay beads were carried out in terms of number of recycles. $97.19 \%$ degradation was obtained in a solar photo-Fenton process after $105 \mathrm{~min}$ at $\mathrm{pH}=3$. Complete mineralization of 2C14NP was confirmed through reduction in COD along with the disappearance of the parent compound peak in HPLC chromatograms.
\end{abstract}

Keywords: Photocatalysis; Photo-Fenton process; Degradation; Cement beads; Clay beads

\section{INTRODUCTION}

2-Chloro-4-nitrophenol (2Cl4NP) is one of the toxic and complex compounds commonly used as an intermediate in both the pesticide and pharmaceutical industries. Ingestion, absorption through the skin and inhalation of 2Cl4NP is harmful as it causes irritation to the skin, gastrointestinal tract, eyes and respiratory tract. The adverse effects of these types of compounds on human health and environment due to their alarming concentrations in water bodies have been reported (Konstantinou et al., 2001). The excessive use of pesticides, fertilizers, pharmaceutical wastes and even small amount of industrial effluents are mainly responsible for the pollution of surface and groundwater (Chiron et al., 2000; Gleick, 2002; Misra et al., 2013).

The existence of pharmaceuticals in various water sources has been cited in the literature (Stackelberg et al., 2004; Rabiet et al., 2006; Nikolaou et al., 2007; Ryu, 2013). Non-biodegradability, toxicity, persistence as well as bio-magnification of these organic compounds make it necessary to adopt appropriate methods for treatment of such compounds. Conventional treatment methods are not sufficient enough for the complete removal of these recalcitrant compounds.

\footnotetext{
* To whom correspondence should be addressed
} 
In the past few years, advanced oxidation processes (AOPs), including heterogeneous and homogeneous photocatalysis, have proven their credentials with a wide range of applications. Suitable band gap semiconductors such as $\mathrm{TiO}_{2}$ are used as catalysts in heterogeneous photocatalysis to generate the reactive oxygen species (ROS). $\mathrm{TiO}_{2}$ photocatalysis is a clean and economical water treatment technology that does not require any addition of chemical consumables and, moreover, it does not generate any hazardous waste products (Duffy et al., 2004; Trabelsi et al., 2016). Post removal of catalyst from the slurry hinders its commercial viability, although better surface area is available in suspension form (Gurr et al., 2005). Alternatively the catalyst can be immobilized on an inert support (Borges et al., 2015), which promotes its stability along with recyclability. However, many studies have been reported in literature regarding the fixing of catalyst on support materials like ceramic paper (Vereb et al., 2014), glass plates, cemented slabs, alginate beads (Verma et al., 2014a), cement beads (Verma et al., 2014b), granular expanded clay (Pronina et al., 2015). Cost-effective inert supports and their durability for prolonged use is still an existing need.

The photo-Fenton process offers no mass transfer limitations because of its homogeneous catalytic nature and there is no thermal energy involved as the catalyst makes the process easy to run and control (Neyens and Baeyens, 2003). The presence of a light source speeds up the photoFenton reaction, thereby causing fast decomposition of $\mathrm{H}_{2} \mathrm{O}_{2}$ by ferrous or ferric ions, resulting in the formation of radicals. Though homogenous photocatalysis leads to higher removal rate (Kwon et al., 1999), removal of iron ions at the end of treatment is quite expensive and difficult. However in a heterogeneous photo-Fenton process, the catalyst is easily recovered either by filtration or sedimentation and can be used again. Different iron sources can be used as heterogeneous catalysts. Different iron oxides and iron powder have been tested (Lucking et al., 1998). Different materials can be used as hetero-Fenton catalysts, including Fe-treated laponite, iron exchanged zeolite (Tekbas et al., 2008), iron loaded resin (Cheng et al., 2004), $\mathrm{Fe}_{3} \mathrm{O} 4, \mathrm{Fe}_{2} \mathrm{O} 3$ and S-doped $\mathrm{Fe}_{2} \mathrm{O}_{3}$ (Feng et al., 2004).

The present study attempts the photodegradation of 2Cl4NP using cement beads and clay beads coated with $\mathrm{TiO}_{2}$ (investigations not reported earlier). The process is optimized in slurry mode to select the better /optimized conditions for degradation of 2Cl4NP. Durability of the support is confirmed by effectively recycling the coated beads. Attempts have also been made to carry out the degradation of 2Cl4NP through a heterogeneous solar photo-Fenton process using Foundry sand as an alternative iron source.

\section{MATERIALS AND METHODS}

\section{Chemicals}

Technical grade (97\%) 2-Chloro-4-nitrophenol (2Cl4NP), $\mathrm{ClC}_{6} \mathrm{H} 3\left(\mathrm{NO}_{2}\right) \mathrm{OH}$ (Figure $\mathrm{S} 1$ ) was obtained from Sigma Aldrich and used as such without any further purification. $\mathrm{TiO}_{2}$ (a mixture of Anatase and Rutile form of titanium dioxide in the ratio of 70:30) obtained from Evonik Industries, India, was used as a photocatalyst. Hydrogen Peroxide $\left(\mathrm{H}_{2} \mathrm{O}_{2}\right)(30 \% \mathrm{w} / \mathrm{v})$ (Ranbaxy laboratories) was used as an oxidant/electron acceptor. Concentrated $\mathrm{HCl}$ and $\mathrm{NaOH}$, obtained from Merck were employed for adjusting the $\mathrm{pH}$. In the solar photo-Fenton reaction, waste foundry sand (FS) was received from a local industry as a gift sample and used without any modifications. Double distilled water was used in all the experiments.

\section{Immobilization of $\mathrm{TiO}_{2}$ on cement and clay beads}

Different sized spherical cement beads (around 200 in number) were made manually using an appropriate amount of cement and sand. Around 50 beads of uniform size (13 $\mathrm{mm}$ diameter) were chosen for immobilization. Similarly spherical shaped clay beads were made using clay. Beads were coated with $\mathrm{TiO}_{2}$ through a dip coating method as mentioned in previous studies (Verma et al., 2014b). Two coatings were sufficient for a uniform layer of catalyst on the beads. After each coating, the beads were calcined at $400 \mathrm{oC}$ for proper catalyst intactness. The beads were washed with water after the final coating to remove loosely intact catalyst particles. Figure 1(a) and $1(\mathrm{~b})$ shows $\mathrm{TiO}_{2}$ coated cement and clay beads, respectively.

\section{Experimental Procedure}

A $1000 \mathrm{~mL}$ borosilicate glass bowl $(17 \mathrm{~cm}$ diameter and $5 \mathrm{~cm}$ height) was used as a batch reactor for photocatalytic reactions. The batch reactor was placed on a laboratory jack in a wooden UV chamber $(1.37 \mathrm{~m} \times 0.9 \mathrm{~m} \times 1.0 \mathrm{~m})$. Eight 36W UV tubes (Philips), which have a wavelength of $365 \mathrm{~nm}$, were attached on the underside of the roof to get the required intensity for degradation (Toor et al., 2006). The UV tubes were switched on 30-40 minutes prior to the start of the experiment for a stabilized photon flux. The UV intensity was varied between 10 and $25 \mathrm{Wm}-2$ by adjusting the distance between reactor and the tubes. The UV intensity was measured using an Eppley radiometer (model no.-33013). For controlling the temperature of the chamber, an exhaust fan was provided and temperature was maintained in the range of $30-35 \mathrm{oC}$ throughout the experiment. A working solution of $50 \mathrm{mg} \mathrm{L}^{-1}$ was made by dissolving $50 \mathrm{mg}$ of $2 \mathrm{Cl} 4 \mathrm{NP}$ in $1 \mathrm{~L}$ of double distilled water with continuous stirring overnight and the solution was stored at room temperature. 

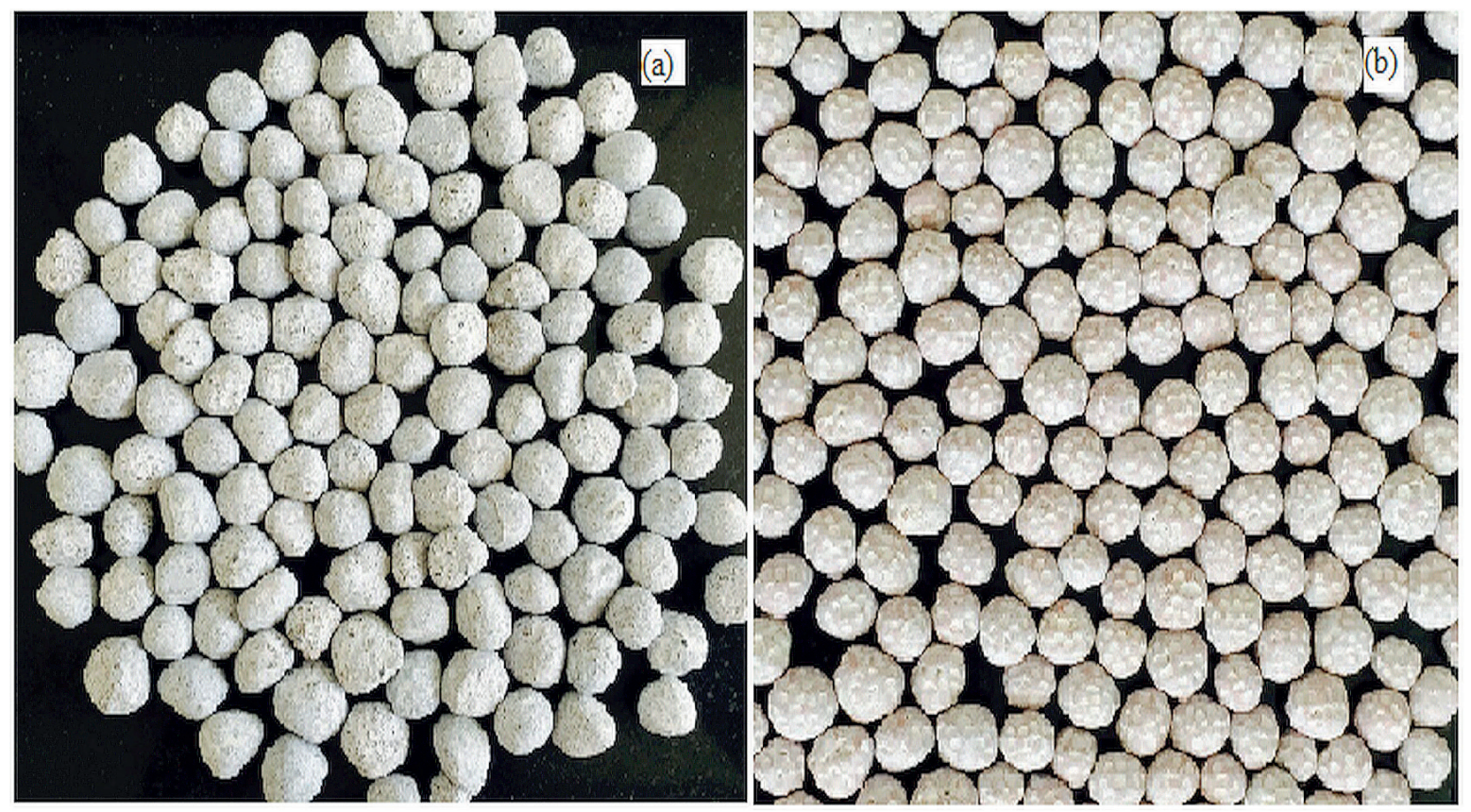

Figure 1. (a) $\mathrm{TiO}_{2}$ coated cement beads and (b) $\mathrm{TiO}_{2}$ coated clay beads.

For slurry and immobilized photocatalysis, $50 \mathrm{mgL}^{-1}$ of 2Cl4NP solution $(200 \mathrm{~mL})$ was taken in a batch reactor. A suitable amount of $\mathrm{TiO}_{2}$ was added to the solution in the case of slurry photocatalysis and aeration was done by spargers. In the immobilized studies, a sufficient number of $\mathrm{TiO}_{2}$ coated beads covering the entire bottom surface of the reactor was used and two spargers were used for aeration to maintain the homogeneity of reaction. Photo-Fenton studies were carried out using same reactor (as mentioned above) under natural solar light. Known amounts of FS and the oxidant $\mathrm{H}_{2} \mathrm{O}_{2}$ were added to the aqueous solution of 2Cl4NP. The reactor was placed on a magnetic stirrer for continuous stirring except for fixed-bed studies. At regular intervals of time, a sample was collected (3-4 mL) from the vessel and was filtered through a $0.45 \mu \mathrm{m}$ syringe filter. Analysis of these samples was done by UV-Vis spectrophotometer.

Different operating parameters like the effect of photocatalyst, UV intensity, $\mathrm{pH}, \mathrm{FS}$ concentration, addition of oxidant, $\mathrm{A} / \mathrm{V}$ ratio were studied and optimized in photocatalytic as well as photo-Fenton processes. All solar experiments were carried out during the months from April to June, 2015 , from 10 A.M. to 4 P.M. at Patiala (30.3400 ${ }^{\circ}$ $\mathrm{N}, 76.3800^{\circ} \mathrm{E}$ ), India. The experiments were performed thrice for reproducibility of results. For all the experiments, the standard deviation was in the range of 3-5\%.

\section{Chemical Analysis}

The degradation of 2Cl4NP was studied using a UVVis spectrophotometer (HITACHI model no. U-2800), using the $\lambda \max$ at $266 \mathrm{~nm}$. HPLC [Shimazdu, SED-20A] analysis was also carried out for confirming 2Cl4NP degradation. HPLC was conducted with a binary HPLC system with C-18 column $(250 \mathrm{~mm} \times 4.60 \mathrm{~mm})$, particle size $5 \mu \mathrm{m}$ using acetonitirile:water (70:30) as mobile phase with UV detection at $266 \mathrm{~nm}$ for 2Cl4NP. Flow rate was maintained at $1.0 \mathrm{~mL}$ min-1. Standard methods as per the American Public Health Association (APHA) were used to measure iron (APHA 2012: Sec. 3111(B)), aluminum (APHA 2012: Sec. 3111(D)) for FS, COD (APHA 2012: Sec. 5220 (D)) and nitrate ions (APHA, 1989: Sec. 4500NO3 (E)).

\section{RESULTS AND DISCUSSION}

\section{Photolytic and Adsorption studies}

In the current study, adsorption and photolytic experiments were carried out as control prior to photocatalytic studies. Photolysis studies were performed in a batch reactor by irradiating the 2Cl4NP solution with UV light (UV only) in the absence of photocatalyst in which only a negligible amount of degradation $(6 \%)$ was observed. Adsorption studies ( $\mathrm{TiO}_{2}$ only) showed $7.5 \%$ reduction in the concentration of $2 \mathrm{Cl} 14 \mathrm{NP}$, which may be due to the development of a monolayer of pollutant on the surface of the catalyst. The formation of monolayer blocks all active sites on the surface of the catalyst, due to which no further decrease in degradation was observed. In the presence of oxidant $\left(\mathrm{H}_{2} \mathrm{O}_{2}\right.$ only), almost $10 \%$ degradation of the compound was observed. The combination of $\mathrm{H}_{2} \mathrm{O}_{2}$ $+\mathrm{TiO}_{2}+\mathrm{UV}$ showed $91.75 \%$ degradation in $120 \mathrm{~min}$, as 
depicted in Figure 2. Blank experiments were performed using bare cement and clay beads (without catalyst coating), which led to $8.5 \%$ and $7 \%$ reduction in the concentration of compound after $5 \mathrm{~h}$, whereas $6 \%$ degradation of compound was attained in the presence of only foundry sand. It can therefore be presumed that adsorption-desorption of 2Cl4NP along with reaction intermediates are reasonably slower than electron/hole pair formation (Lapertot et al., 2007).

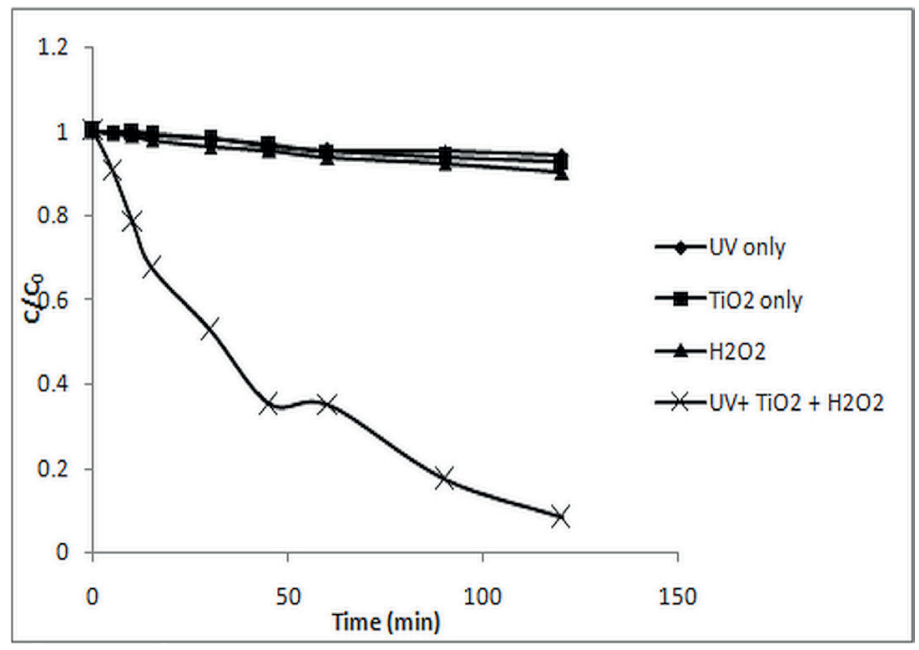

Figure 2. Preliminary experiments performed under different conditions to evaluate their efficiency towards degradation of 2Cl4NP.

\section{Photodegradation kinetics}

Kinetics of photocatalytic reactions are now well established to be first order according to a LangmuirHinshelwood (L-H) kinetic model, i.e.,

$$
-\mathrm{dC} / \mathrm{dt}=\mathrm{kC} \Rightarrow \ln (\mathrm{CO} / \mathrm{C})=\mathrm{kt}
$$

The value of the rate constant, $\mathrm{k}$, was evaluated by plotting a linear graph between the natural logarithm of the

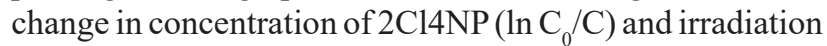
time, $\mathrm{t}$, and was then further used in kinetic studies.

\section{Heterogeneous photocatalysis using suspended $\mathrm{TiO}_{2}$}

\section{Effect of $\mathrm{TiO}_{2}$ concentration}

Photocatalyst concentration greatly affects the rate of photocatalytic reaction as an optimized catalyst concentration ensures effective absorption of all the photons (Saquib and Muneer, 2003). Overdose of catalyst causes a reduction in the penetration of light into the solution as well as undesirable scattering of light (Chun et al., 2000). To determine the optimum concentration of $\mathrm{TiO}_{2}$, it was varied between $0.5-1.5 \mathrm{gL}^{-1}$. The degradation rate increased with increase in catalyst loading up to 1.0 $\mathrm{gL}^{-1}$ and thereafter started declining at higher catalyst dose (Figure 3(a)), which may be due to the above discussed reasons. The other reason for this might be the decrease in catalyst surface area available for light absorption at higher concentration of catalyst. The number of active sites on the surface of the catalyst increases with the increase in the catalyst amount, but after a certain dose penetration of light gets affected due to an excessive particle concentration. However, there was a very slight increase in the value of the degradation rate $\mathrm{k}$ from $0.007-0.0075 \mathrm{~min}-1$ when the $\mathrm{TiO}_{2}$ dose was increased from $0.75-1.0 \mathrm{~g} \mathrm{~L}^{-1}$; the optimized dose of photocatalyst selected in our study was $0.75 \mathrm{~g} \mathrm{~L}^{-1}$ as the lower catalyst dose is always preferred for commercial applications.

\section{Effect of $p H$}

In the present study, the $\mathrm{pH}$ was varied between 4 and 9 with the optimized dose of $\mathrm{TiO}_{2}$, i.e., $0.75 \mathrm{~g} \mathrm{~L}^{-1}$ and maximum degradation was achieved in acidic conditions, i.e., at $\mathrm{pH} 4$ (Figure $3 \mathrm{~b}$ ). The value of the degradation rate constant $\mathrm{k}$ decreased from $0.008976 \mathrm{~min}-1$ to $0.001 \mathrm{~min}-$ 1 with the increase in the $\mathrm{pH}$ from 4 to 9 . $\mathrm{TiO}_{2}$ depicts the amphoteric nature as its surface shows positive and negative charge below and above the point of its zero charge at $\mathrm{pH} 6.5$, as is clear from the following equations (Verma et al., 2013):

$$
\begin{gathered}
\mathrm{TiOH} \rightleftharpoons \mathrm{TiO}^{-}+\mathrm{H}^{+} \\
\mathrm{TiOH}+\mathrm{H}^{+} \rightleftharpoons \mathrm{TiOH}_{2}^{+}
\end{gathered}
$$

For the $\mathrm{HO}_{2}$ radical, a higher $\mathrm{pH}$ value $(>\mathrm{pKa})$ leads the reaction to move in the reverse direction. The insufficient 
amount of $\mathrm{HO} 2$ radicals hinders the degradation process. Therefore, the reaction of positive holes with water and $\mathrm{OH}-$ on the surface of titanium dioxide leads to the generation of $\mathrm{OH}$ free radicals. Okamoto et al. (1985) reported that generation of $\mathrm{OH}$ free radicals was basically from $\mathrm{H}_{2} \mathrm{O}_{2}$, which did not favor the degradation of 2Cl4NP at a high $\mathrm{pH}$ region. The optimized $\mathrm{pH}$ for all reactions in our study was 4 .

\section{Effect of oxidant addition}

The role of adding oxidants or electron acceptors in $\mathrm{TiO}_{2}$ photocatalysis is now well established. The oxidants not only prevent the recombination of electron/hole by acquiring the electron from the conduction band, but also promote the production of more oxidizing species and hydroxyl radicals, thereby improving the degradation rate (Singh et al., 2007a, 2007b, 2007c). In our study, to determine the optimum concentration of oxidant $\left(\mathrm{H}_{2} \mathrm{O}_{2}\right)$, it was varied from 0.05 to $0.3 \mathrm{~mL} / 200 \mathrm{~mL}$ at the optimized dose of $\mathrm{TiO}_{2} 0.75 \mathrm{gL}^{-1}$ and $\mathrm{pH} 4$. Figure 3(c) shows that the rate constant of the degradation reaction of 2Cl4NP initially increased when $\mathrm{H}_{2} \mathrm{O}_{2}$ was added in the range of $0.05-0.1 \mathrm{~mL} / 200 \mathrm{~mL}$. Thereafter, the degradation rate started declining as the scavenging effect of electron/hole predominates at higher concentration of $\mathrm{H}_{2} \mathrm{O}_{2}$ and formation of $\mathrm{HO} 2$ occurs (Zhao et al., 2004). 96\% degradation of 2Cl4NP was achieved with $0.1 \mathrm{~mL} / 200 \mathrm{~mL}$ of $\mathrm{H}_{2} \mathrm{O}_{2}$ in the optimized conditions after $120 \mathrm{~min}$ of photocatalytic treatment.
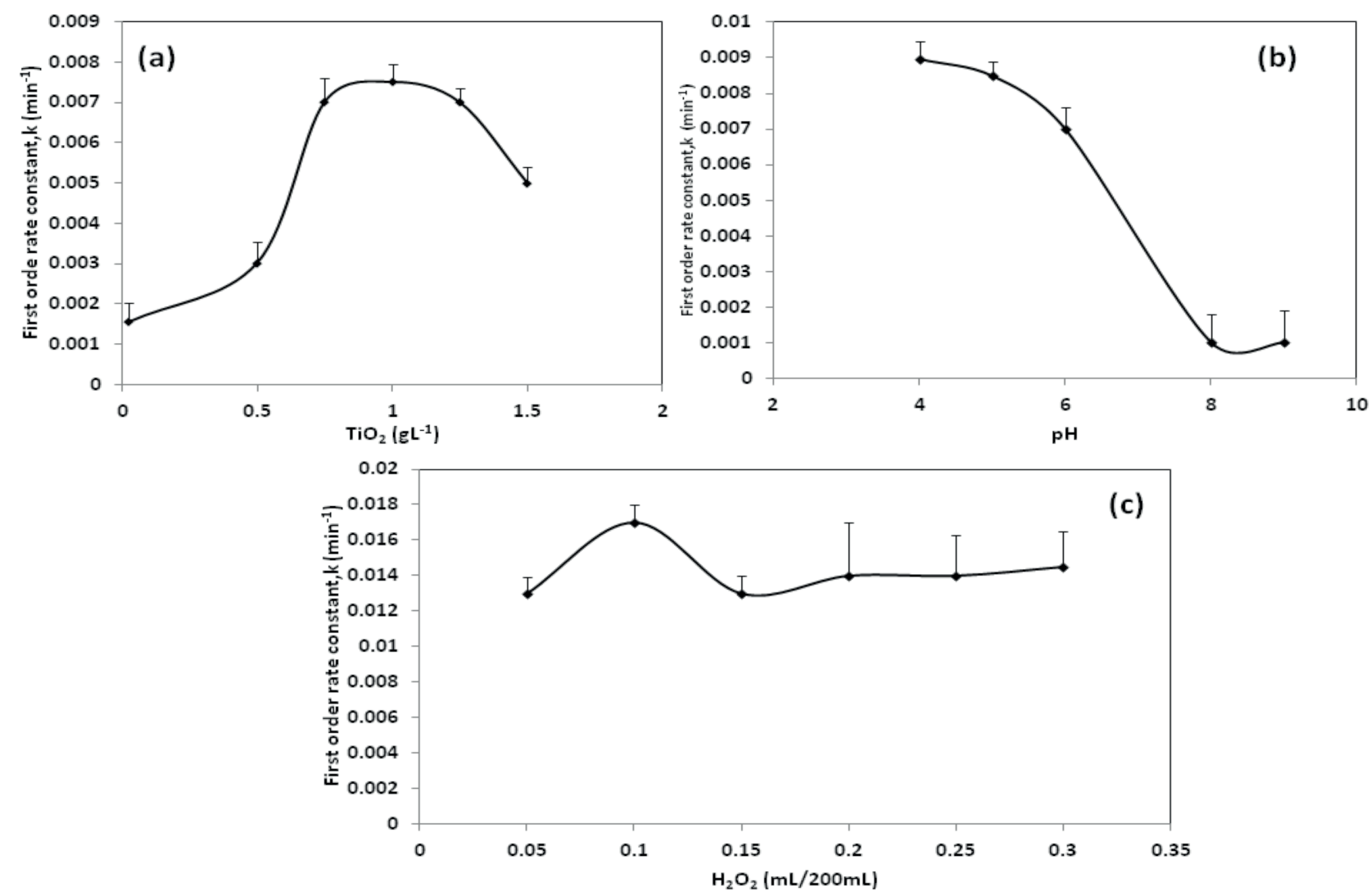

Figure 3. Plot of first order rate constant, $\mathrm{k}$ vs variation in $\mathrm{TiO}_{2}$ (a), variation in $\mathrm{pH}$ (b), variation in $\mathrm{H}_{2} \mathrm{O}_{2}$ (c) during photocatalytic degradation of 2Cl4NP.

\section{Effect of UV intensity}

The radiation absorption capacity of catalyst greatly influences the photocatalytic reaction rate (Curco et al., 2002; Karunakaran and Senthilvelan, 2005; Qamar et al.,
2006). To study this effect, the UV intensity was varied from 10-25 W m-2 under optimized conditions for the degradation of 2Cl4NP. The degradation rate constant was found to be increased from 0.014 to $0.017 \mathrm{~min}-1$ as the UV intensity was increased from $10 \mathrm{~W} \mathrm{~m}-2$ to $25 \mathrm{~W}$ 
m-2 (Figure 4(a)). This might be because of the increase in the production of electron/hole pair on the surface of photocatalyst with increase in light intensity, thereby improving the oxidation of the organic pollutant. In our study, the electrical energy consumption for the treatment of $200 \mathrm{~mL}$ of working solution for 2 hours was $12 \mathrm{kWh} / \mathrm{m} 3$ as per the literature (Daneshvar et al., 2007).

Effect of $\mathrm{A} / \mathrm{V}$ ratio of the reactor

To study the influence of $\mathrm{A} / \mathrm{V}$ ratio of the reactor on the degradation of $2 \mathrm{Cl} 4 \mathrm{NP}$, the photocatalytic reactions were carried out in a batch reactor under all optimized conditions. Area by Volume (A/V) of the reactor was varied between $0.907-2.268 \mathrm{~cm} 2 \mathrm{~mL}^{-1}$. For better degradation, the effective penetration of light (either UV or solar) into the aqueous solution to be treated is very important and, for this, a greater $\mathrm{A} / \mathrm{V}$ ratio, i.e., greater area with lesser depth is desired (Toor et al., 2006). In our case A/V was varied by altering the volume of solution used in the reactor keeping the exposed area constant. It can also be altered the other way by keeping volume of the solution constant and varying the area of exposure. As the volume of the solution was lowered, i.e., increasing the $\mathrm{A} / \mathrm{V}$ ratio, the degradation rate constant of 2Cl4NP increased from 0.011 min- 1 to 0.02 min-1 as shown in Figure 4(b). The increase in degradation is because the depth of the solution decreases and the path length of photons entering the solution increases, resulting in elevated production of $\mathrm{OH}$ radicals (Verma et al., 2014c).
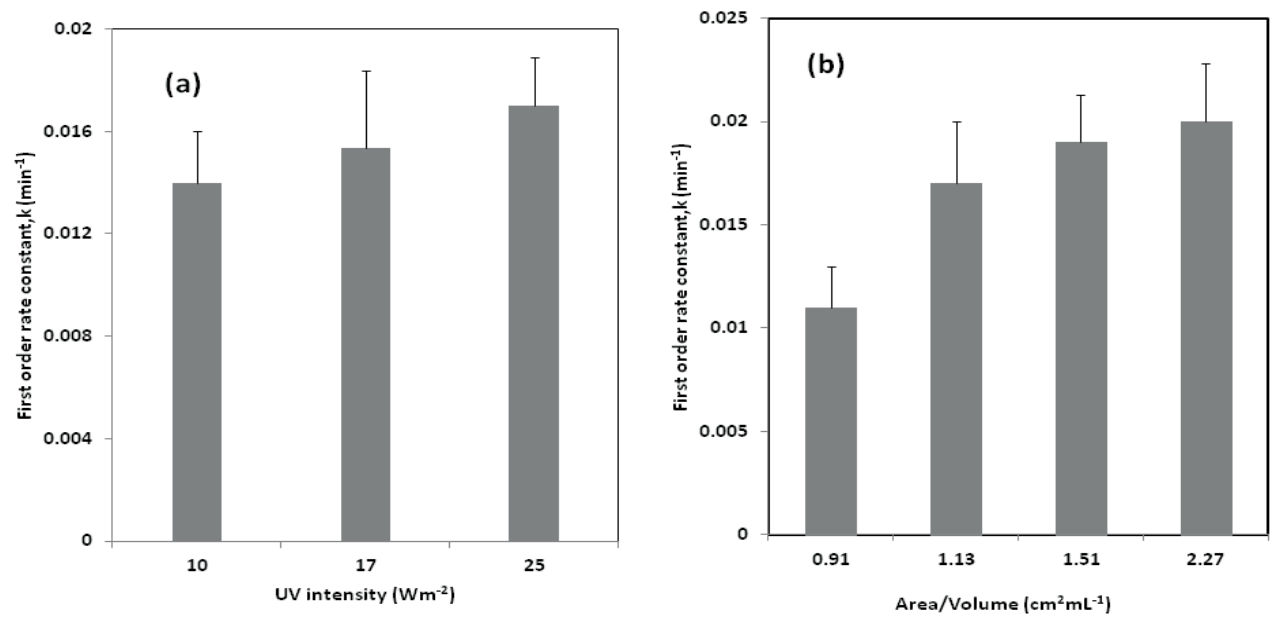

Figure 4. Plot of first order rate constant, $k$ vs variation in UV intensity (a), variation in $\mathrm{A} / \mathrm{V}$ ratio (b) during photocatalytic degradation of $2 \mathrm{Cl} 4 \mathrm{NP}$.

\section{Heterogeneous photocatalysis using supported $\mathrm{TiO}_{2}$}

Degradation of $2 \mathrm{Cl} 4 \mathrm{NP}$ using $\mathrm{TiO}_{2}$ immobilized on cement and clay beads

To off-set the drawbacks of slurry photocatalysis, fixedbed studies have been performed for the photodegradation of 2Cl4NP using two different supports (cement beads and clay beads) for the immobilization of $\mathrm{TiO}_{2}$. Experiments were conducted in sunlight using appropriate number of cement beads and clay beads in a batch reactor containing an aqueous solution of 2C14NP under all optimized conditions in slurry photocatalysis. $68 \%$ and $52 \%$ degradation of
2Cl4NP was obtained after $5 \mathrm{~h}$ of photocatalytic treatment using cement beads and clay beads, respectively, as depicted in Figure 5. The $\mathrm{pH}$ of the solution continuously increased during the course of reaction and degradation decreased (as discussed in the $\mathrm{pH}$ section). For this reason, the acidic $\mathrm{pH}$ of the solution was maintained by continuous addition of acid to sustain the degradation of 2Cl4NP. With certain modifications, a continuous/semi-continuous solar reactor can be designed with optimized parameters for field-scale applications. In fact this is the first reported study for the degradation of 2Cl4NP using clay beads and cement beads as inert support material for immobilization of the catalyst. 


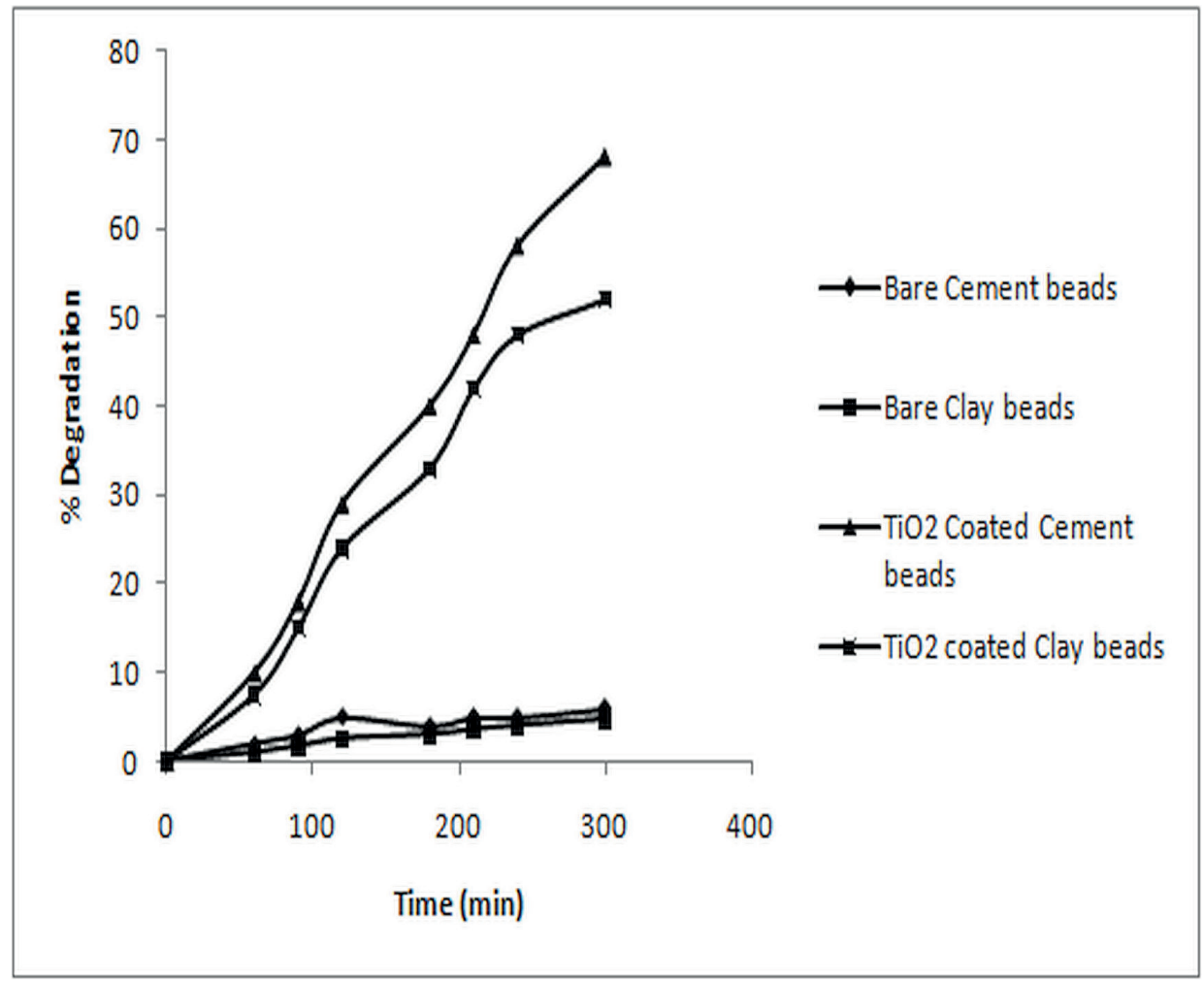

Figure 5. Degradation of $2 \mathrm{Cl} 4 \mathrm{NP}$ by bare cement and clay beads and effect of $\mathrm{TiO}_{2}$ coated cement and clay beads.

\section{Recyclability Studies}

In fixed-bed photocatalysis, the durability of supported catalyst is very important aspect as far as its field-scale applications are concerned. The activity of immobilized catalyst decreases after certain runs due to either catalyst fouling or loss of catalyst from the surface. Some studies have reported high temperature $\left(480^{\circ} \mathrm{C}\right)$ reactivation of the catalyst, which is generally not good from an economical point of view. With this view, efforts have been done to check the durability of immobilized catalyst on cement and clay beads for the degradation of 2Cl4NP. The cement and clay beads were recycled for 10 cycles without much decrease in its photocatalytic efficiency for degradation of 2Cl4NP as shown in Figure 6(i). For reactivation of the beads, they were heated in an oven or muffle at $100^{\circ} \mathrm{C}$ for one hour after every cycle. Photocatalytic activity of the beads may have reduced somewhat because of the loss of catalyst during the reaction or blocking of catalyst sites. Scanning electron microscope (SEM) images and Energydispersive X-ray spectroscopy (EDS) analysis showed that the catalyst was intact on clay and cement beads even after 10 cycles as shown in Figure 6(ii) and 6(iii), which proved its stability. More effective methods of catalyst immobilization, durable support and efficient reactor design can prevent/minimize the aforesaid problems.

\section{Degradation studies using the solar photo-Fenton process:}

\section{Effect of oxidant addition}

In the present study, $\mathrm{H}_{2} \mathrm{O}_{2}$ was varied between 0.05 and $0.25 \mathrm{~mL} / 200 \mathrm{~mL}$ for degradation of 2Cl4NP solution by keeping the other conditions constant ( $\mathrm{pH} 3, \mathrm{FS}=0.1 \mathrm{gm})$. Figure 7 (a) shows that $93.56 \%$ degradation was achieved at $0.05 \mathrm{~mL} \mathrm{H}_{2} \mathrm{O}_{2}$ and thereafter degradation decreased, which might be due to the prevailing scavenging effects of hydroxyl radical. The Fenton reaction is inhibited by an excessive amount of hydrogen peroxide as it reacts with hydroxyl radical and produces a less reactive hydroperoxyl radical according to equation (3) (Walling, 1975).

$$
\mathrm{H}_{2} \mathrm{O}_{2}+\mathrm{HO}^{\cdot} \rightarrow \mathrm{HO}_{2}^{\cdot}+\mathrm{H}_{2} \mathrm{O}
$$

Also in the oxidation reaction, an excess amount of $\mathrm{H}_{2} \mathrm{O}_{2}$ reacts with ferric ions, yielding $\mathrm{Fe}$ (III)- hydroperoxy complexes (Laat and Gallard, 1999), which reduces the ferrous ions required for the Fenton reaction.

\section{Effect of foundry sand concentration}

Ferrous iron behaves like a catalyst in the Fenton reaction, which directs the oxidation of pollutants. In our study, foundry sand was used as an alternative iron source 


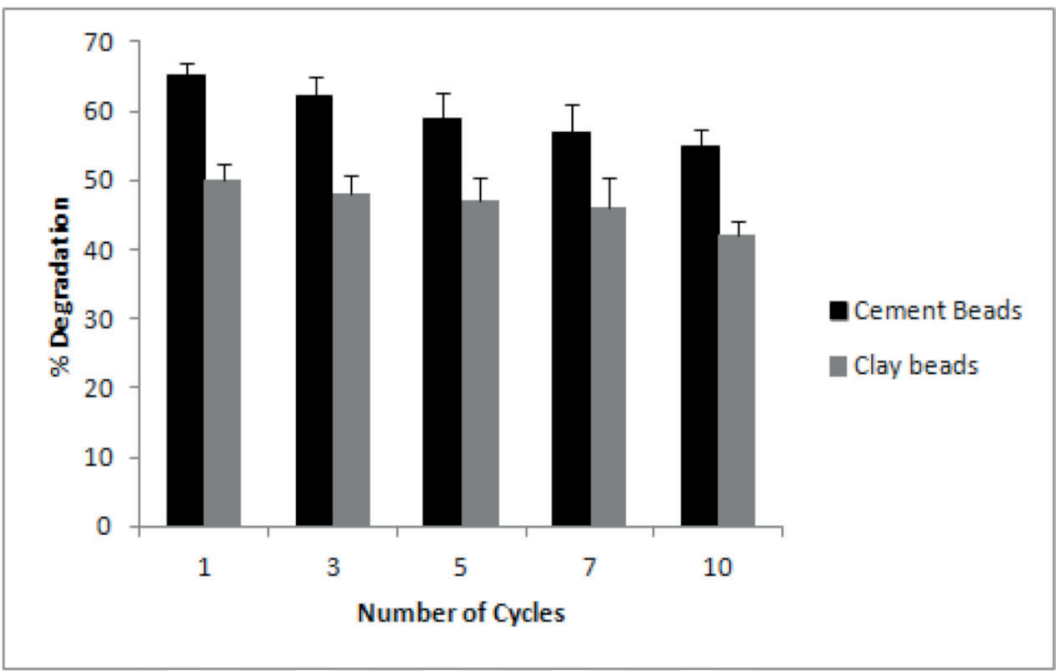

Figure 6(i). Recyclability Studies of $\mathrm{TiO} 2$ coated cement and clay beads for the degradation of 2Cl4NP.

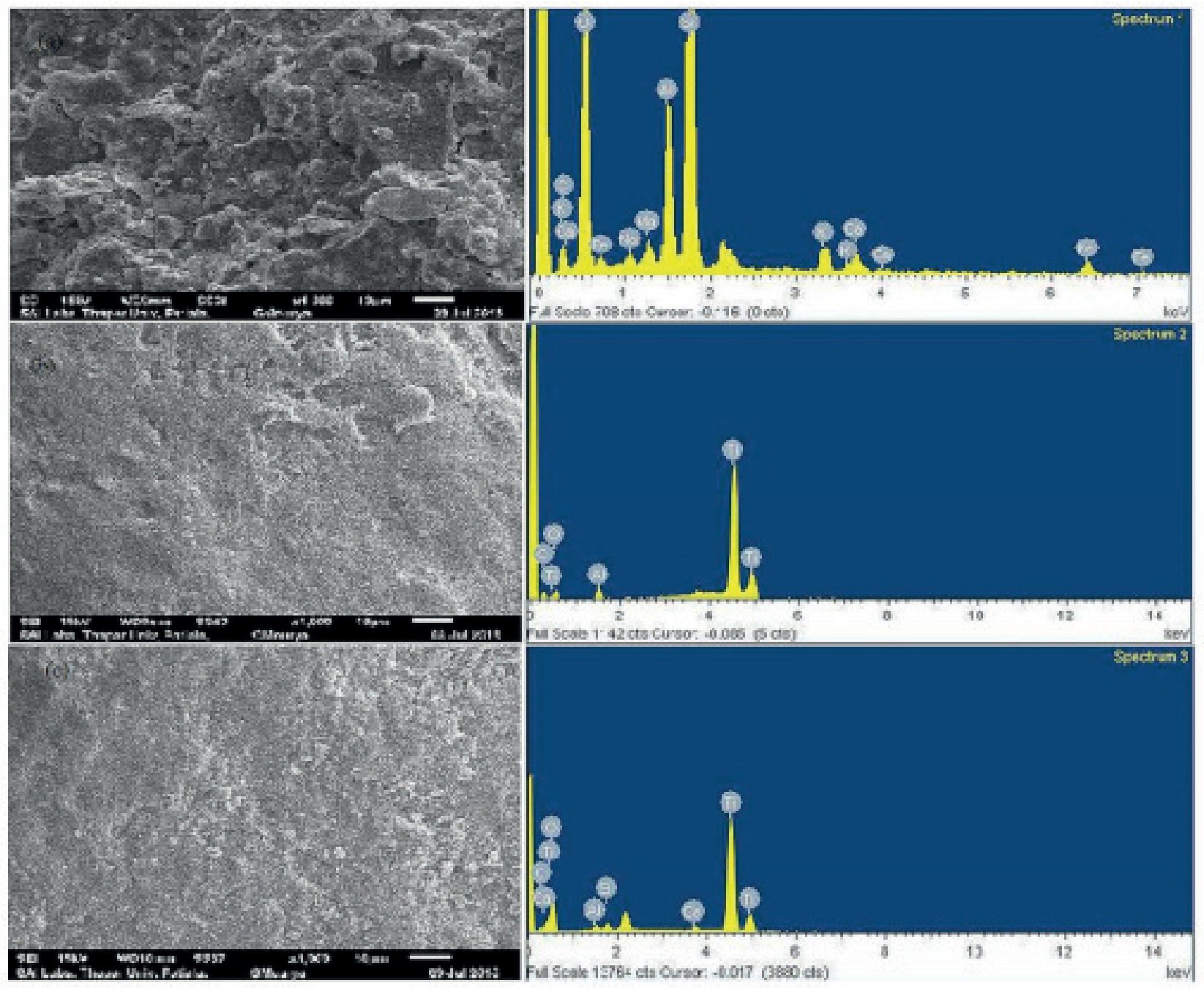

Figure 6(ii). SEM images (a) blank clay bead without TiO2 coating (b) freshly coated TiO2 clay bead (c) used clay bead after 10 cycles along with their EDS data. 


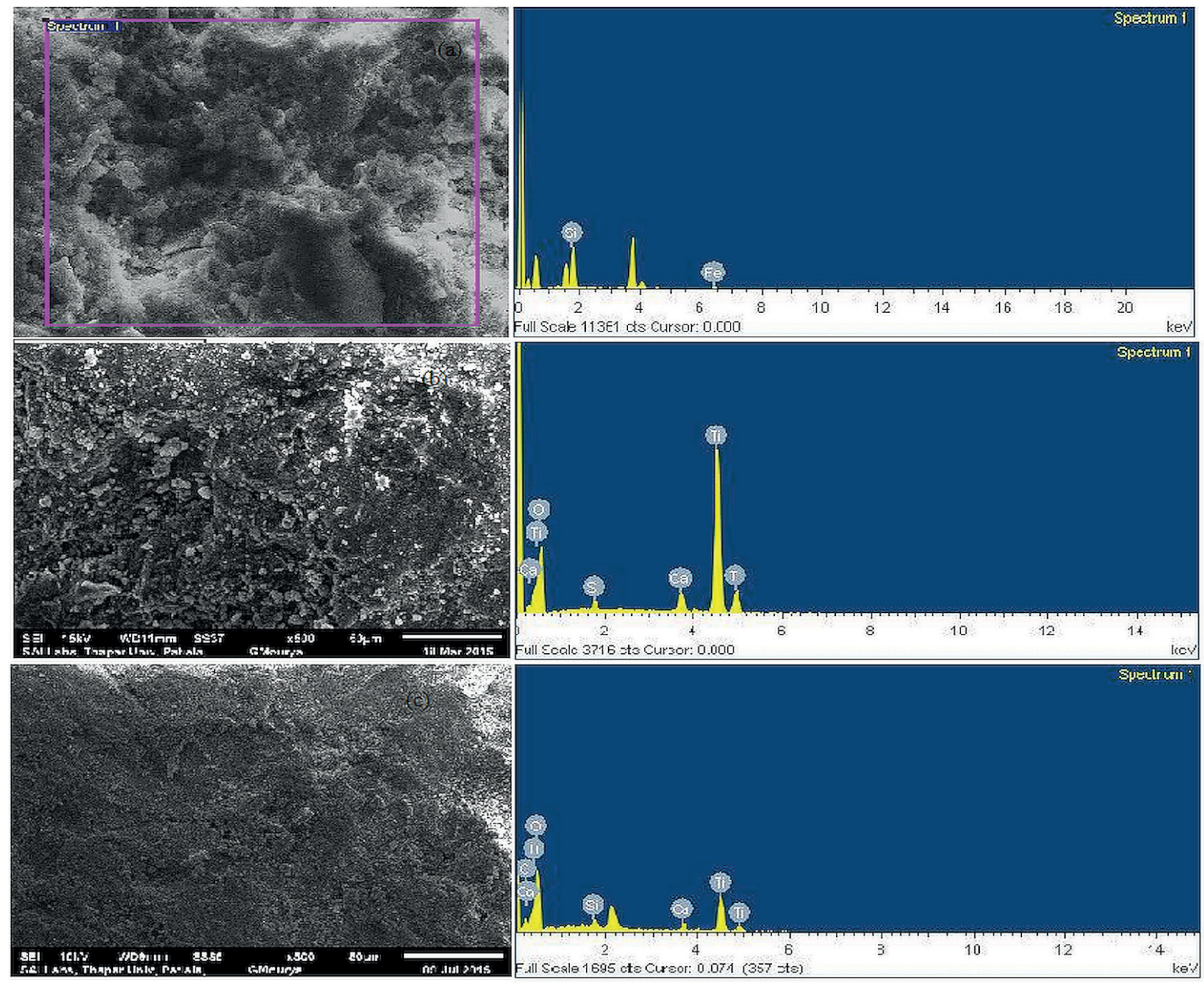

Figure 6(iii). SEM images (a) blank cement bead without $\mathrm{TiO}_{2}$ coating (b) freshly coated $\mathrm{TiO} 2$ cement bead (c) used cement bead after 10 cycles along with their EDS data.

since SEM-EDS analysis of FS confirmed the presence of iron and aluminum required for the Fenton reaction. FS was varied between $0.05-0.25 \mathrm{~g}$ at the optimized dose of $0.05 \mathrm{~mL} \mathrm{H}_{2} \mathrm{O}_{2}$ and $\mathrm{pH} 3$. It was observed that the removal efficiency of 2Cl4NP increased with an increase in addition of FS from $0.05 \mathrm{~g}$ to $0.1 \mathrm{~g}$ and then started decreasing with further addition (figure $7 \mathrm{~b}$ ). The reason for the initial increase in degradation of 2Cl4NP is the consumption of $\mathrm{H}_{2} \mathrm{O}_{2}$ by ferrous ions, thereby increasing the production of more hydroxyl radicals. Excessive ferrous iron $(>0.1$ g) shows a scavenging effect of hydroxyl radical, thus reducing the degradation rate, as depicted in equation 4 (Buxton et al., 1988). After $60 \mathrm{~min}$, degradation was similar for different amounts of sand (0.05-0.25 g), but we selected $0.1 \mathrm{~g}$ sand because the rate of degradation is fast as compared to the others and $97.19 \%$ degradation was achieved in $105 \mathrm{~min}$.

$$
\mathrm{OH}+\mathrm{Fe}^{2+} \rightarrow \mathrm{OH}-+\mathrm{Fe}^{3+}
$$

\section{Effect of Iron Leaching}

Handling and disposal of FS is difficult and it adds other pollutants to water, posing a threat to the environment. Efforts have been made in the present study to leach out iron from foundry sand in dissolved form to carry out photoFenton studies. For this, iron was leached in acidic water (pH 3) by dipping $0.1 \mathrm{gm}$ of sand in $200 \mathrm{~mL}$ distilled water for $1 \mathrm{hr}$. Atomic Absorption Spectroscopic (AAS) analysis of the above solution revealed the presence of sufficient amounts of iron $\left(0.26 \mathrm{mgL}^{-1}\right)$ and aluminum $\left(<2.5 \mathrm{mgL}^{-1}\right)$ which can be used in the solar photo-Fenton reaction as catalyst. It can therefore be indicated that the iron:2Cl4NP dose used was 0.0052 . The reaction was carried out in sunlight with an average intensity of $25 \mathrm{Wm}-2$ adding $0.05 \mathrm{~mL} \mathrm{H}_{2} \mathrm{O}_{2}$ to the above solution. $87 \%$ degradation was achieved in $180 \mathrm{~min}$ as shown in Figure 7(c). 

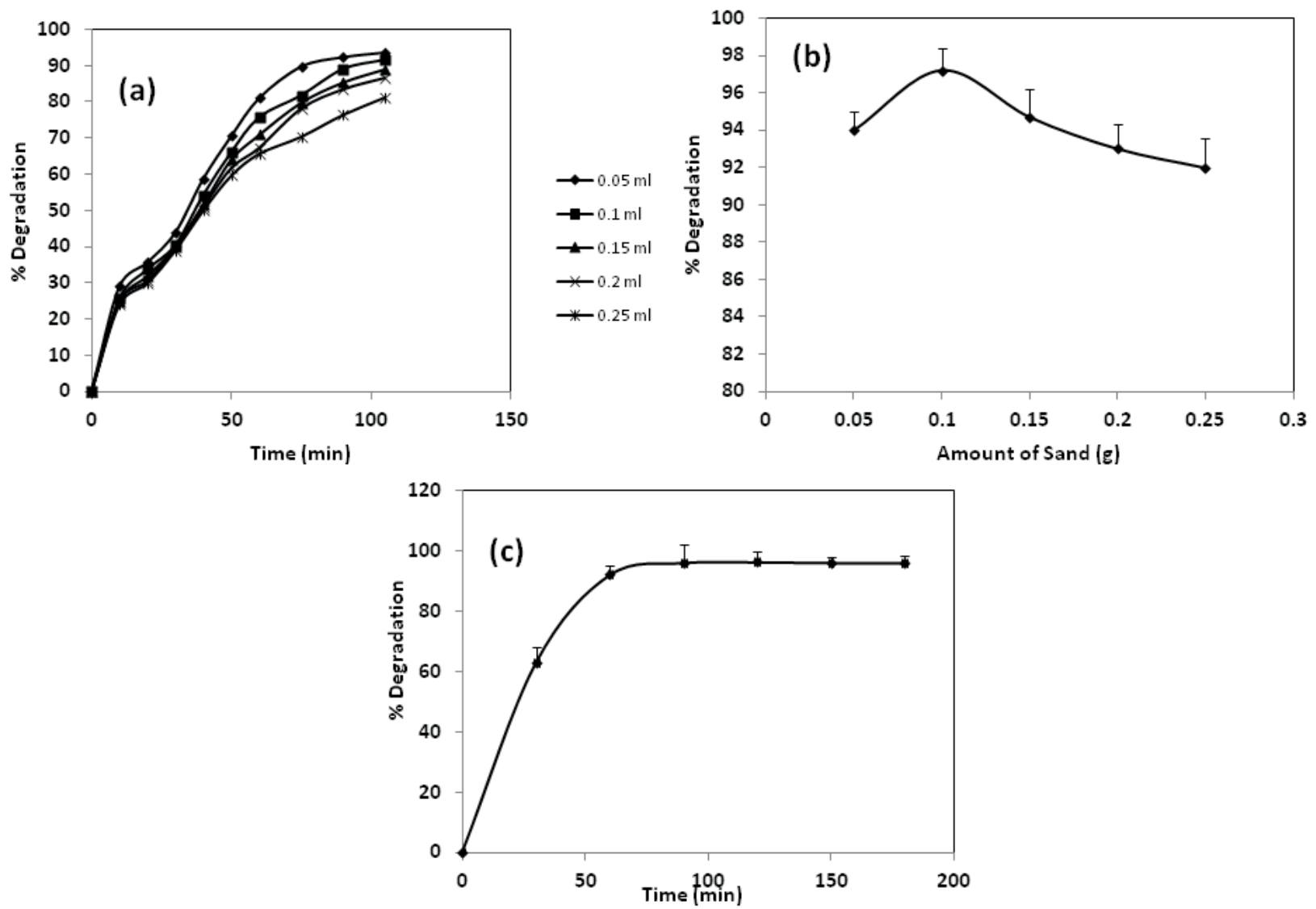

Figure 7. Percentage degradation of $2 \mathrm{Cl} 4 \mathrm{NP}$ at varying (a) concentration of $\mathrm{H}_{2} \mathrm{O}_{2}$ (b) concentration of Foundry sand (c) Effect of leached out iron from FS on 2Cl4NP degradation during photo-Fenton Process.

\section{Mineralization Studies}

Transformation of all the carbon atoms into gaseous $\mathrm{CO} 2$ and the hetero-atoms to inorganic anions confirms the complete mineralization of pollutant (Evgenidou et al., 2005). The subsequent degradation of the compound was confirmed through HPLC analysis as peaks of the parent compound almost disappeared in HPLC chromatograms after $75 \mathrm{~min}$ of treatment (Figure S3), but the reaction continued to $2 \mathrm{~h}$ so that the other impurities/intermediates present may be degraded, which was subsequently confirmed through COD and nitrate ion generation. Approximately a $75 \%$ decrease in COD along with $85 \%$ production of nitrate ions was observed after $2 \mathrm{~h}$ of treatment (Figure S2).

\section{CONCLUSIONS}

The photodegradation efficiency of heterogeneous photocatalysis using slurry, immobilized form and heterogeneous solar photo-Fenton process (using FS) has been evaluated for the degradation of 2C14NP. Slurry photocatalysis yielded $96 \%$ degradation of 2Cl4NP in 120 min while $52 \%$ and $68 \%$ degradation of the compound was achieved in fixed-bed photocatalysis after $5 \mathrm{~h}$ using clay and cement beads, respectively. In the case of solar photoFenton process, 97.19\% degradation was obtained in 105 min. The optimized values of the operating parameters in the case of $\mathrm{TiO}_{2}$ photocatalysis were: $\mathrm{TiO}_{2}=0.75 \mathrm{gL}^{-1}, \mathrm{pH}=$ $4, \mathrm{H}_{2} \mathrm{O}_{2}=0.1 \mathrm{~mL} / 200 \mathrm{~mL}$ and in the case of the solar photoFenton process, the optimized conditions were: $\mathrm{H}_{2} \mathrm{O}_{2}=0.05$ $\mathrm{mL} / 200 \mathrm{~mL}, \mathrm{FS}=0.1 \mathrm{~g}$. The coated beads were effectively recycled for ten cycles, a study reported for the first time. The complete mineralization of 2C14NP was assured with $75 \%$ reduction in COD as well as elimination of the parent compound peak in HPLC chromatograms.

\section{ACKNOWLEDGEMENTS}

This study was supported by a grant from DRDO, New Delhi (India) and The Institution of Engineers (India). 


\section{REFERENCES}

APHA., Standard Methods for the Examination of Water and Wastewater. American Public Health Assoiation., 22nd ed., Washington DC (2012).

Borges, M., García, D. M., Hernández, T., Ruiz-Morales, J. C., and Esparza, P., Supported Photocatalyst for Removal of Emerging Contaminants from Wastewater in a Continuous Packed-Bed Photoreactor Configuration, Catalysts, 5, 77-87 (2015).

Buxton, G.V., Greenstock, C.L., Helman, W.P. and Ross, A.B., Critical-review of rate constants for reactions of hydrated electrons, hydrogen-atoms and hydroxyl radicals (.OH/.O-) in aqueous solution, The Journal of Physical Chemistry, 17, No. 2, 513 (1988).

Cheng, M.M., Ma, W.H., Li, J., Huang, Y.P., Zhao, J.C., Wen, Y.X. and $\mathrm{Xu}$, Y.M.,. Visible light assisted degradation of dye pollutants over $\mathrm{Fe}(\mathrm{III})$ - loaded resin in the presence of $\mathrm{H}_{2} \mathrm{O}_{2}$ at neutral $\mathrm{pH}$ values, Environmental Science and Technology, 38, No. 5, 1569 (2004).

Chiron, S., Fernanadez-Alba, A., Rodriguez, A., and GarciaCalvo E., Pesticide Chemical Oxidaion: State of art, Water Research, 34, No. 2, 366 (2000).

Chun, H., Yizhong, W., and Hongxiao, T., Destruction of phenol aqueous solution by photocatalysis or direct photolysis, Chemosphere, 41, No. 8, 1205 (2000).

Curco, D., Gime'nez, J., Addardak, A., Cervera-March, S., and Esplugas, S., Effects of radiation absorption and catalyst concentration on the photocatalytic degradation of pollutants, Catalysis Today, 76, 177 (2002).

Daneshvar, N., Aber, S., Dorraji, M. S. S., Khataee, A. R., and Rasoulifard, M. H., Preparation and investigation of photocatalytic properties of $\mathrm{ZnO}$ nanocrystals: Effect of operational parameters and kinetic study, International Scholarly and Scientific Research \& Innovation, 1, No. 5, 62 (2007).

Duffy, E.F., Al-Touati, F., Kehoe, S.C., McLoughlin, O.A., Gill L.W., Gernjak, W., Oller, I., Maldonado, M.I., Malato, S., Cassidy, J., Reed, R.H., and McGuigan, K.G.. A novel TiO ${ }_{2}^{-}$ assisted solar photocatalytic batch-process disinfection reactor for the treatment of biological and chemical contaminants in domestic drinking water in developing countries, Solar Energy, 77, No. 5, 649 (2004).

Evgenidou, E., Fytianos, K., and Poulios, I., Photocatalytic oxidation of dimethoate in aqueous solutions. Journal of Photochemistry and Photobiology A, 175, No. 1, 29 (2005).

Feng, J., Hu, X., and Yue, P.L., Discoloration and Mineralization of Orange II Using Different Heterogeneous Catalysts Containing Fe: A Comparative Study, Environmental Science and Technology, 38, No. 21, 5773 (2004).

Gleick, P.H., Dirty-water: Estimated Deaths from Waterrelated Diseases 2000-2020. Pacific Institute for Studies in Development, Environment, and Security (2002).

Gurr, J.R., Wang, A.S., Chen, C.H., and Jan, K.Y., Ultrafine titanium dioxide particles in the absence of photoactivation can induce oxidative damage to human bronchial epithelial cells, Toxicology, 213, No.1, 66 (2005).
Karunakaran, C., and Senthilvelan, S., Photooxidation of aniline on alumina with sunlight and artificial UV light, Catalysis Communications, 6, No. 2, 159 (2005).

Konstantinou, I. K., Sakellarides, T. M., Sakkas, V. A., and Albanis, T. A. Photocatalytic Degradation of Selected s-Triazine Herbicides and Organophosphorus Insecticides over Aqueous $\mathrm{TiO}_{2}$ Suspensions, Environmental Science and Technology, 35, No. 2, 398 (2001).

Kwon, B.G., Lee, D.S., Kang, N., and Yoon, J., Characteristics of p-Chloro-phenol oxidation by Fenton's reagent, Water Research, 33, No. 9, 2110 (1999).

Laat, J., and Gallard, H., Catalytic decomposition of hydrogen peroxide by $\mathrm{Fe}$ (III) in homogeneous aqueous solution: mechanism and kinetic modeling, Environmental Science and Technology, 33, No. 16, 2726 (1999).

Lapertot, M., Ebrahimi, S., Dazio, S., Rubinelli, A., and Pulgarin, C., Photo-Fenton and biological integrated process for degradation of a mixture of pesticides, Journal of Photochemistry and Photobiology A, 186, No. 1, 34 (2007).

Lücking, F., Köser, H., Jank, M., and Ritter, A., Iron powder, graphite and activated carbon as catalysts for the oxidation of 4-chlorophenol with hydrogen peroxide in aqueous solution, Water Research, 32, No. 9, 2607 (1998).

Misra R., Satyanarayan S., and Potle N., Treatment of agrochemical/pesticide wastewater by coagulation/ flocculation process. International Journal of Chemical and Physical Sciences, 2, 38 (2013).

Neyens, E., and Baeyens, J., A review of classic Fenton's peroxidation as an advanced oxidation technique, Journal of Hazardous Materials, 98, No. 1, 33 (2003).

Nikolaou, A., Meric, S., and Fatta, D., Occurrence patterns of pharmaceuticals in water and wastewater environments, Analytical and Bioanalytical Chemistry, 387, No. 4, 1225 (2007).

Okamoto, K. I., Yamamoto, Y., Tanaka, H., Tanaka, M., and Itaya, A., Heterogeneous photocatalytic decomposition of phenol over $\mathrm{TiO}_{2}$ powder, Bulletin of the Chemical Society of Japan, 58, No. 7, 2015 (1985).

Pronina, N., Klauson, D., Moiseev, A., Deubener, J., \& Krichevskaya, M.. Titanium dioxide sol-gel-coated expanded clay granules for use in photocatalytic fluidized-bed reactor, Applied Catalysis B: Environmental, 178, 117 (2015).

Qamar, M., Muneer, M., and Bahnemann, D., Heterogeneous photocatalysed degradation of two selected pesticide derivatives, triclopyr and daminozid in aqueous suspensions of titanium dioxide, Journal of Environmental Management, 80, No. 2, 99 (2006).

Rabiet, M., Togola, A., Brissaud, F., Seidel, J.L., Budzinski, H., and Elbaz-Poulichet, F., Consequences of treated water recycling as regards pharmaceuticals and drugs in surface and ground waters of a medium-sized Mediterranean catchment, Environmental Science and Technology, 40, No. 17, 5282 (2006).

Ryu A., Pharmaceutical pollution of water in India: International market failure, Harvard Health Policy Review, 14, 25 (2013).

Saquib, M., and Muneer, M., $\mathrm{TiO}_{2}$-mediated photocatalytic degradation of a triphenylmethane dye (gentian violet), in aqueous suspensions, Dyes and Pigments, 56, No. 1, 37 (2003). 
Singh,H.K., Saquib, M., Haque, M., Muneera, M., and Bahnemann, D., Titanium dioxide mediated photocatalysed degradation of phenoxyacetic acid and 2,4,5-trichlorophenoxyacetic acid, in aqueous suspensions, Journal of Molecular Catalysis A: Chemical, 264, No. 1, 66 (2007a).

Singh, H. K., Saquib, M., Haque, M., and Muneer, M., Heterogeneous photocatalysed degradation of 4-chlorophenoxyacetic acid in aqueous suspensions, Journal of Hazardous Materials, 142, No. 1, 374 (2007b).

Singh, H.K., Saquib, M., Haque, M.M., and Muneer, M., Heterogeneous photocatalyzed degradation of uracil and 5-bromouracil in aqueous suspensions of titanium dioxide, Journal of Hazardous Materials, 142, No. 1, 425 (2007c).

Stackelberg, P.E., Furlong, E.T., Meyer, M.T., Zaugg, S.D., Henderson, A.K., and Reissman, D.B., Persistence of pharmaceutical compounds and other organic wastewater contaminants in a conventional drinking-water-treatment plant, Science of the Total Environment, 329, No. 1, 99 (2004).

Tekbaş, M., Yatmaz, H.C., and Bektaş, N., Heterogeneous photoFenton oxidation of reactive azo dye solutions using iron exchanged zeolite as a catalyst, Microporous and Mesoporous Materials, 115, No. 3, 594 (2008).

Toor, A.P., Verma, A., Singh, V., Jotshi, C.K., and Bajpai, P.K., Photocatalytic degradation of Direct Yellow 12 dye using UV/ $\mathrm{TiO}_{2}$ in a shallow pond slurry reactor, Dyes and Pigments, 68, No. 1, 53 (2006).

Trabelsi, H., Atheba, G.P., Hentati, O., Mariette, Y.D., Robert, D., Drogui, P., and Ksibi, M., Solar Photocatalytic Decolorization and Degradation of Methyl Orange Using Supported $\mathrm{TiO}_{2}$, Journal of Advanced Oxidation Technologies, 19, No. 1, 79 (2016).

Veréb, G., Ambrus, Z., Pap, Z., Mogyorósi, K., Dombi, A., and Hernádi, K., Immobilization of crystallized photocatalysts on ceramic paper by titanium (IV) ethoxide and photocatalytic decomposition of phenol, Reaction Kinetics, Mechanisms and Catalysis, 113, No. 1, 293-303 (2014).

Verma, A., Kaur, H., and Dixit, D., Photocatalytic, Sonolytic and Sonophotocatalytic Degradation of 4-chloro-2nitro phenol, Archives of Environmental Protection 39, No. 2, 17 (2013).

Verma, A., Dixit, D., Toor, A., and Srivastava, J., Heterogeneous photocatalytic degradation of 2-chloro-4-nitrophenol using slurry and fixed bed reactor, Environmental Progress and Sustainable Energy, 34, No. 2, 380 (2014a).

Verma, A., Prakash, N.T., and Toor, A.P., An efficient $\mathrm{TiO}_{2}$ coated immobilized system for the degradation studies of herbicide isoproturon: Durability studies, Chemosphere, 109, 7 (2014b).

Verma, A., Prakash, N. T., and Toor, A. P., Photocatalytic Degradation of Herbicide Isoproturon in $\mathrm{TiO}_{2}$ Aqueous Suspensions: Study of Reaction Intermediates and Degradation Pathways, Environmental Progress and Sustainable Energy, 33, No. 2, 402 (2014c).

Walling, C., Fenton's reagent revisited. Accounts of Chemical Research, 8, No. 4, 125 (1975).

Zhao, H., Xu, S., Zhong, J., and Bao, X., Kinetic study on the photocatalytic degradation of pyridine in $\mathrm{TiO}_{2}$ suspension systems, Catalysis Today, 93, 857 (2004). 